\title{
Editorial
}

\section{SURGICAL REHABILITATION}

Leprosy would be easy to cure if it was only a disease of the skin but its seriousness comes from the fact that it is also, and mainly, a disease of peripheral nerves. Even if medication can ensure bacterial cure, many leprosy patients continue to develop incapacities ${ }^{5-67}$ from which these questions arise: why are they always located in the extremities? what is the pattern of these deformities and mutilations? and which problems can be partly solved by reconstructive surgery?

Because technical requirements and the training of surgeons varies from country to country the aim is not to define the best surgical treatments or techniques but to develop concepts and techniques which enable as many leprosy patients as possible to be treated with the means that are available in their country. In relation to the aim of 'Health for all by the year 2000', I would like to think that by the year 2000 all leprosy patients will have the benefit of the medical means available in the environment where they live.

\section{Patterns of deformities in leprosy}

\section{CLASSIFICATION OF THE DISTAL SITES OF DEFORMITIES}

The pathogenesis of leprosy neuritis is based on the destruction of Mycobacterium le prae in nerve trunks causing inflammatory and immunological phenomena, with cellular and oedematous infiltration, resulting in the swelling of nerve trunks; this produces a form of 'hypertrophic' neuritis. At the same time, the epineurium thickens and becomes rigid leading to a mechanical internal compression. Certainly this enlargement is seen in anatomical regions in which nerve trunks lie superficial, in the limb, just under the skin, where tissues are occasionally below body temperature, a factor contributing to the damaging reaction which takes place. ${ }^{33}$ But in these superficial regions, the swollen nerve trunks pass through unyielding osteofibrous tunnels, as Guadagnini ${ }^{49}$ has shown. These tunnels are normally moulded around nerve trunks of normal size. When there is nerve involvement, steroid treatment and rest by splinting are sometimes not enough to suppress the immunological and inflammatory response in the nerve and to relieve the intraneural tension by decreasing oedema and inflammation. Then the element of superadded mechanical external compression determines the site of the functional deficit of nerve trunks-these compression sites are: $:^{8-49}$ 
The ulnar nerve: at the elbow, under the epitrochlear-olecranon ligament and under the arch formed by the flexor carpi ulnaris muscle origin, producing claw hand;

the median nerve: at the wrist, under the carpal ligament, producing opponens function loss; both ulnar and median nerve damage producing palmar hand sensory loss;

the lateral popliteal nerve: at the knee, under deep fascia behind the neck of the fibula and under the arch formed by the peroneus longus muscle origin, producing foot drop;

the tibialis posterior nerve and the origin of plantar nerves: at the ankle, under the flexor retinaculum and at the entrance of the plantar tunnels, producing clawed toes and particularly sole sensory loss;

the facial nerve: in temporalis tunnel and/or above the zygomatic arch and across the fascia of the parotid gland, producing facial paralysis and particularly lagophthalmos which is often the cause of corneal ulcers.

Involvement of the radial nerve is very rare ( 3 cases of 438 ulnar nerve involvements in a series recorded in 1979). ${ }^{27}$ Evidence of these external compressions has been shown by lipiodal neurographies ${ }^{10}$ and recently both external and internal pressure of median nerve have been measured by computerized microcaptors. ${ }^{42}$ The clinical signs of nerve involvement are: thickening, tenderness or pain, sensory impairment with abnormal sensation such as a burning feeling and numbness.

Nerve trunk damage will produce the following:

Pain (in reactional neuritis, severe neuralgic pain may cripple patients overnight), nevertheless, it is not always associated to the other clinical signs;

Sweating loss, in the area of the nerve;

Motor loss of which the resulting disabilities are few: claw fingers and thumb opposition loss, foot drop, clawing of toes and lagophthalmos. Thus, only a few techniques will be necessary to correct these deformities and the surgeon can use multiple muscles innervated by median or radial nerve at the forearm or by posterior tibialis nerve at the calf, which will never be paralysed - this is the opposite of poliomyelitis paralysis in which there are a lot of deformities and therefore corrective techniques;

Sensory loss: It extends to the nerve trunk's distribution, most often without patches; it is different from the limited sensory loss of patches which is very superficial and may occur anywhere in the body.

\section{PATHOGENESIS OF ULCERS AND MUTILATIONS}

Because of sensory loss of hands or soles of the feet, the leprosy patients do not feel pain due to trauma, high or repetitive moderate stress, burns or infection. They continue to use a wounded and infected limb without sensation and subject it to stress in spite of infection. This leads to skin wounds, ulcers, damage and infection of soft tissues, joints and bones and then to absorbence, which months or years later, causes gradual 'spontaneous' amputation of fingers, toes, or parts of hands and feet. All this condemns patients to repeated dressings (the cost of which is considerable), for many years, bef ore undergoing the so called 'required' surgical amputations.

In addition to these deformities and disabilities which are the consequence of leprotic neuritis, the deformities directly caused by infection with $M$. leprae are few: Flat nose, loss of eyebrows, specific ocular lesions (iridocyclitis, cataract) gynecomastia. 


\section{Place of surgery in the care of deformities}

There are two aims - to restore the most important lost anatomical functions and to correct the appearance of leprosy patients.

\section{RECONSTRUCTIVE SURGERY}

\section{Motor paralysis}

Reconstructive surgery can correct most of the deformities due to motor paralysis. The limbs should be kept mobile and preoperative exercises are necessary to prevent joints becoming stiff or to reduce stiffness, particularly in the fingers and ankles. The skin must be free of ulceration or contracture (if there are contractures after exercises and splintage, skin-plasty or full thickness skin graft may be necessary).

All the techniques used for the correction of traumatic paralysis give similar mechanical results for leprosy paralysis, provided that the surgeons are experienced in these techniques and in their indications. ${ }^{8-22}$ The only, but very important, difference is that in leprosy, hands and feet often have definitive sensory loss.

\section{Hand deformities}

Claw fingers: The paralysis of the intrinsic muscles of the hand leads to claw hand; this deformity makes grasp and pinch movements difficult, and adapted tools, large handles or grip aids are useful, although often not available. Surgery can restore motor function loss and also correct the appearance (which is a cause of social rejection). Because of sensory loss all accurate finger movements must not always be restored (e.g. finger spacing or abduction of the index finger, partially restored by transfer in the radial edge of the first phalanx, become awkward and it is better to restore a 'bidigital hand', that can grasp objects between the thumb and the four fingers acting together, by fixing the transfer in the ulnar side of the index). ${ }^{8-21,25-32}$ Furthermore, excessive prehension strength is to be avoided because it affects the trophicity of extremities submitted to repetitive stress. ${ }^{33}$

Possible postoperative complications should be known, the most frequent of which is 'intrinsic plus' hypercorrection, it is due to the too powerful action of the transfer ${ }^{25-32}$ and to the loss of the strong antagonist action on the 2nd phalanx of the FDS tendon disinserted. It should also be acknowledged that the FDS is a very active anterior ligament of the PIP joint, as described in $1961,{ }^{25}$ and this explains why hypercorrection can occur after a simple disinsertion of the FDS as after the lasso operation, or even after slackening of the FDS as in flexor pulley advancement. ${ }^{22}$

Many operations can be used and the choice is made according to the training of the surgeon in hand reconstructive surgery, also to the degree of joint stiffness, time of procedures, postoperative exercises needed and the technical requirements. Here are the operations currently performed.

Intrinsic reactivation procedures: these operations use tendon transfer in such a way as to simulate the paralysed intrinsic muscles.

\section{Transfer to the lateral band of the expansion of interossei}

Stiles-Bunnell's operation was the first used. A flexor digitorum sublimis tendon is 
transferred to the expansion of its own finger. ${ }^{25-31}$ It does give very good results but the use of a powerful muscle to replace a weak intrinsic muscle of a mobile finger can result in overcorrection, which develops into a postoperative 'intrinsic plus' deformity. To prevent this, Bunnell \& Littler have proposed to use only one tendon sublimis for the four fingers.

Fowler's operation: ${ }^{45}$ the transfer of extensor proprius of the index and 5 th fingers divided in two strips is not easy to perform because of the insufficient length of the transferred tendon to allow a good suture. It may however be useful to correct failure of another operation.

Brand's operation ${ }^{32}$ uses an extensor carpi radialis lengthened with a many-tailed free tendon graft. This procedure uses either dorsal, interosseous route or carpal tunnel route and gives very good results. But this operation is a long process and to add a new tendon through the carpal tunnel may produce median nerve compression.

Giraudeau's operation: ${ }^{48}$ the flexor carpi radialis is lengthened with fascia lata using the carpal tunnel route after the opening of the carpal ligament. It provides good results.

\section{Transfer to the tendon of interossei}

Palande's operation ${ }^{59}$ uses the extensor carpi radialis longus lengthened with fascia lata and fixes the strip on the tendon of interossei; a complementary transfer of a tail to the hypothenars aims at a better restoration of a reversed metacarpal arch.

\section{Transfer in the pulley}

Zancolli's lasso operation: ${ }^{71}$ the FDS tendon is removed from its insertion on the medial phalanx in order to be sutured to itself after making a loop through the proximal pulley of flexor sheath. It provides only an independent proximal interphalangeal flexion (PIP) then extensor tendons can extend PIP and DIP joint. Results are good and this simple procedure needs only a palmar incision; but the removal of the tendon sublimis that is a strong anterior ligament of the PIP has given intrinsic plus deformity in rare cases. To prevent this complication:

Boucher has proposed the use of only one tendon for two fingers;

Van Droogenbroeck uses only a slip of tendon sublimis;

Palande uses tendon flexor carpi radialis longus lengthened with fascia lata.

Chevallard's operation: ${ }^{43}$ In a simpler manner, Chevallard ${ }^{15}$ sutures the FDS tendon directly to the pulley by non-resorbable thread without any section of FDS tendon. Of all the procedures this is the quickest to perform.

Passive stabilization of metacarpo phalangeal joint (MCPJ): The restriction of MCPJ hyperextension allows the extensor tendon to extend PIP and DIP joints.

Tenodesis: free tendons are used to prevent MCPJ hyperextension; Srinivasan uses tenodesis ${ }^{63}$ from extensor (in the dorsum of the hand) to extensor (in the first phalanx) passing volar to the deep transverse metacarpal ligament.

Zancolli's capsulorraphy: ${ }^{69,70}$ the shortening of anterior capsule of MCPS to restrict its extension is performed using either a $U$ shaped capsular incision or an orange quarter resection or a transosseous fixation. These procedures correct the clawing but cannot restore the sequence of flexion of fingers. The procedure of capsular-shortening is simplified by an $\mathrm{H}$-shaped capsular incision ${ }^{8,9.22}$ and an added accurate pulley advancement ${ }^{8.9 .25}$ restores a normal closing sequence of fingers.

Dermodesis: Srinivasan uses shortening of palmar skin ${ }^{64}$ to reduce MCPJ hyperexten- 
sion associated with the pulley advancement procedure; this is a very simple and safe procedure. All these interventions demand a 10-15 $\mathrm{MCPJ}$ flexion at rest which some patients do not accept.

Proximal interphalangeal arthrodesis. Exceptionally indicated in very stiff flexion of fingers it allows the flexor a pinch or a little grasp movement.

Conditions of the hand: The finger joints should be as mobile as possible; passive and active exercises will prevent or cure joint stiffness. ${ }^{1}$ The extensor system must be normal. In endemic areas, general surgeons must often undertake operations for leprous claw hand without very special hand surgery training and the techniques must be simple. ${ }^{8}$ For more than 30 years, to help them in indications for palliative surgery of claw hand, I have taken into account four levels of PIP joint stiffness, which enables one to propose a simple therapeutic scheme, based on the stabilization test. 7,8,15,20,25 This test evaluates: interphalangeal stiffness; range of movements; efficacy of extensors. The indications are related to the degree of stiffness and give consistently good results, as shown by the comparative recording of 222 hand operations. ${ }^{22}$

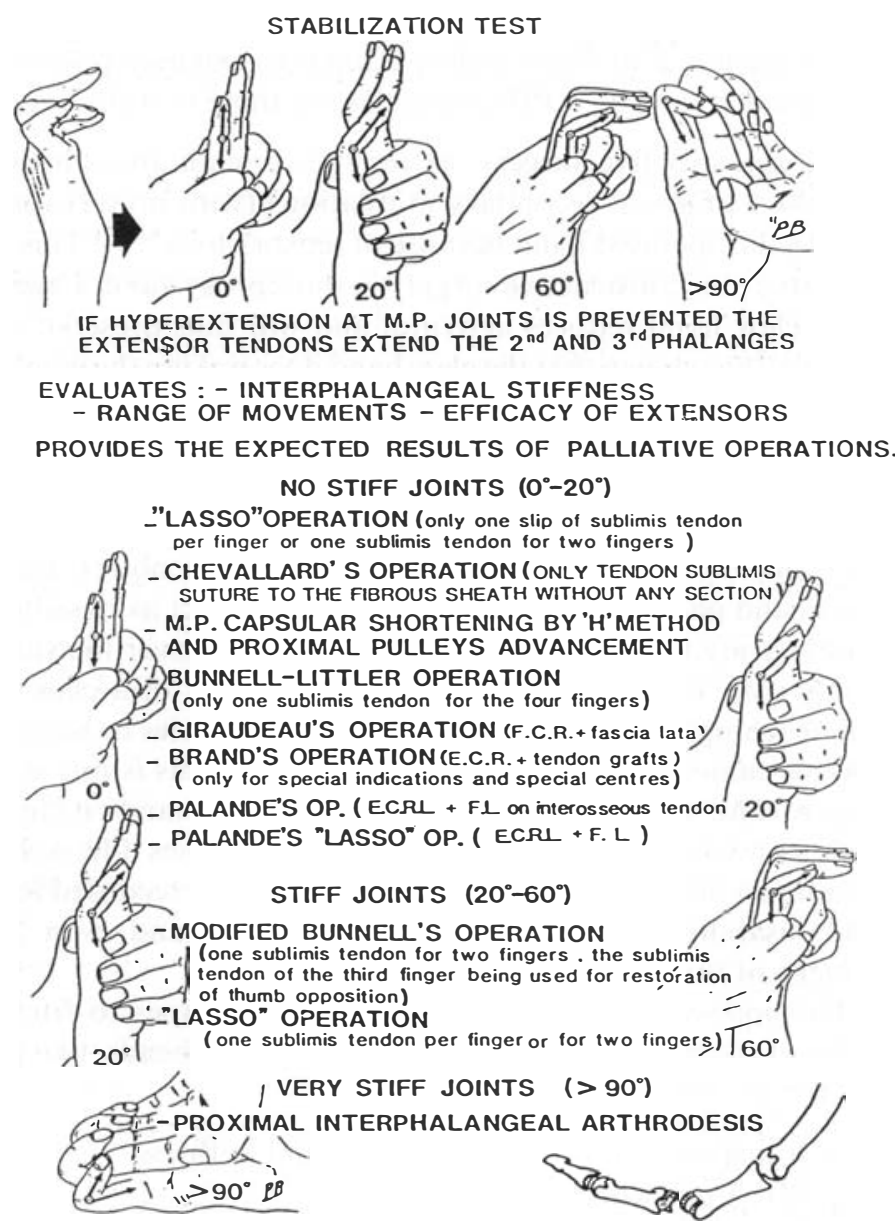


Reconstruction of thumb opposition: The aim is to provide an abductor-rotator of the thumb. Many operative procedures could be used but the two most widely performed are:

Flexor digitorum sublimis transfer: first proposed by St Bunnell, there are a variety of routes to the thumb. My choice ${ }^{8-14}$ is a modified Thompson's operation with FDS of the middle finger passed around the ulnar border of the palmar aponeurosis at the lower border of the carpal ligament; one tendon strip is then passed over the dorsum of the metacarpal head and attached to the adductor insertion; the other tendon strip is attached to both the extensor tendon of the thumb at the middle of the first phalanx and to the abductor pollicis brevis so as to prevent its undesirable secondary slipping, and probably acts as a tenodesis preventing MCPJ hyperextension. Nevertheless this very good procedure uses a FDS tendon and, when there is no finger joint stiffness, intrinsic plus deformities can be induced.

Extensor indicis proprius transfer: a modified and simplified procedure ${ }^{11}$ of Burkhalter's operation uses EIP rerouted directly around the ulnar side of forearm and attached both to the extensor tendon of the thumb at the middle of the first phalanx and to abductor pollicis brevis. This procedure gives good opposition of thumb but the associated claw thumb is not always corrected and this transfer must be completed by transfer of the distal radial half of flexor pollicis longus to extensor pollicis longus at the middle of proximal phalanx, or by a PIP arthrodesis if there is stiff joint. "

Of course, after reconstructive surgery, extremities remain anaesthetic. Unfortunately, perhaps in $25-30 \%$ of cases, secondary mutilations (with preservation of restored function) will occur in the operated hand because of sensory loss. ${ }^{8,15,21}$ This has prompted a discussion of the value of reconstructive surgery in the leprosy hand, Faget $\&$ Mayoral $^{46}$ in 1944 argued that claw hand reduces activities and will thus preserve the hand from trauma. In fact, Brand ${ }^{33}$ has shown that the claw hand does not use the whole of its palmar surface for carrying heavy objects but only the tip of the fingers; this represents a pressure ten times as strong as the pressure exerted on a normal hand. This misuse of the finger tips is for Brand one of the most important causes of finger absorption because of subcutaneous necrosis leading to scarring. When motor function of an anaesthetic hand has been restored, 'this hand will wrap the fingers around the object, so that all of the surface of the fingers and palm surrounds as much of the object as possible. In this way, the actual strain of bearing the weight of the object is spread over the surface of all the fingers and not only over the surface of the tip of the finger of a claw hand'. Health education ${ }^{5.55,67}$ and teaching how to prevent or to treat any injuries or burns ${ }^{66}$ is necessary so that minor injuries cannot become major 'disasters'; but this is not always effective. Long ago, Anaxogore said: 'man is intelligent because he has a hand'; it could also be said that 'the leprosy patient will preserve his hand and his extremities if he is intelligent', and this is observed in almost $60-70 \%$ cases. In my practice I have recorded leprosy patients who have had no disabilities or mutilations for 19 years and even 24 years after reconstructive surgery of the hand.

Clawed toes: To suppress the exposure of the tip of the toes to friction strains or ulceration and stress of the sole over the prominent metatarsal heads, two procedures are generally used with good results:

Flexor-extensor transposition, if the toes are without stiffness.

Arthroplasty of PIP joint, when there is stiffness. 


\section{Foot drop}

Double tendon transfer, a technique proposed by Carayon in $1953,{ }^{40}$ seems to be the best way to correct the paralysis of the dorsiflexors and the evertors of the foot. ${ }^{6}$ Using an interosseous route, the transfer of the tibialis posterior tendon into the tibialis anterior tendon corrects varus and drop foot, while the transfer of the flexor digitorum communis tendon into both the extensor hallucis tendon and the extensor digitorum tendons completes correction of varus and drop foot and also gives active extension of toes and eversion of the foot. This procedure is performed exclusively in the leg above the ankle, far from any possible recently healed plantar ulcer. This double transfer will then give more strength than the single tendon transfer of tibialis posterior. When there is stiffness of the ankle with inability to passive preoperative dorsiflexion, a lengthening of tendo Achillis must be performed.

Single tendon transfer of tibialis posterior, first proposed by Watkins in 1954, nevertheless is better known and most frequently performed, using either interosseous or circumtibial route, as proposed by $\mathrm{Ober}^{56}$ in 1953, with many procedures of distal insertion.

Triple arthrodesis (of subtalar, talonavicular and calcaneo-cuboid joints) a technique that is rarely used now because its action is passive, and thus will deteriorate; the postoperative immobilization for 5 months is too long; and there are risks of bone infection and of nonunion.

Lagophthalmos: To insure the cornea is covered during sleep there are two techniques:

Lateral tarsorraphy, of half the orbital margin, is a simple technique, easy to perform by non-specialized surgeons.

Active muscle transplant ${ }^{3-35}$ uses a fascicle of temporalis muscle and is a technique for specialized surgeons when the cornea is sensitive.

\section{Timing of palliative surgery}

Operate when patterns of paralysis are stable: no increasing paralysis; no recovering muscle function; before severe stiffness develops; without an episode of reaction; 6 months after the beginning of MDT. Surgery should be undertaken 6-12 months after the onset of paralysis.

\section{Strategy and tactics}

Reconstructive surgery needs experienced surgeons, but in the surgical treatment of motor paralysis a delay in surgery of some weeks does not matter if joint stiffness is prevented, ${ }^{2,5,8,66}$ with the exception of corneal ulcers for which temporary tarsorraphy may be needed as an emergency. The first possibility is to send these patients to the nearest place where a competent surgeon can operate on them. ${ }^{8}$ The second is to ask a surgeon experienced in reconstructive surgery to come to the hospital for a limited period of time ${ }^{15}$ to operate on the patients who have been assembled, and at the same time teach a less experienced surgeon of the local hospital how to operate on 
SENSORY LOSS

Because sensory loss is the main complication of leprosy and the cause of most mutilations, attempts to restore sensation are of great interest.

A neurovascular skin island pedicle graft $^{53}$ transfers sensation from a relatively unimportant part of the hand to an insensitive area where a protective sensation is necessary. This technique is rarely possible because of widespread sensory loss.

Nerve grafts: cutaneous nerves usually used for autografts are not available because of their frequent involvement by the disease. Gye $\mathrm{e}^{50}$ and $\mathrm{McLeod}^{54}$ have used grafts from fresh cadavers, freeze-dried, irradiated and immunosuppressive agents; out of 23 nerve allografts, McLeod had only 2 good results with ulnar nerves (graft lengths were from 7 $\mathrm{cm}$ for a median nerve to $31 \mathrm{~cm}$ for a cubital nerve). The problems encountered were the large length of autografts which are necessary and the difficulty of determining exactly where the nerves are affected proximally and distally. Nevertheless, other research trials are needed to correct this important disability.

PLASTIC COSMETICS SURGERY

\section{Usual operations}

Reconstruction of the nose: Replacement of the scarred mucosa by skin graft and support of the ridge of the nose by bone graft. ${ }^{3-33}$

Gynecomastia: Removal of the enlarged gland by circum areolar incision.

\section{Exceptional operations}

Reconstructive surgery of the paralysed hand does not correct wasting of interosseous muscle, particularly between thumb and index metacarpal. In some countries or for some leprosy patients this interosseous wasting remains an obvious stigma of the disease. Three procedures have been performed to mask this wasting: Dermis graft, ${ }^{5}$ injectable liquid silicone ${ }^{44}$ and silastic implant. ${ }^{68}$ Nevertheless, we can say that today it is an 'unnecessary luxury' operation, even if it has a psychological effect.

SURGICAL CARE OF ULCERS AND INFECTION OF EXTREMITIES

\section{Hand}

Pulp and bone infection and necrosis may extend to the synovial sheaths in the palm or the forearm. As for non-leprosy patients, they need incisions and drainages and sometimes amputations. Palmar ulcers may need skin flap.

\section{Foot}

Plantar ulcers are one of the most disabling deformities. They lead to infection of deep tissues, joints and bone, which need incision, drainage, sequestrectomy, metatatarsectomy, metatarsophalangeal joint excision and finally distal and then proximal amputations. These amputations are a disaster in endemic countries because of the lack of special footwear or artificial limbs. 
Treatment of plantar ulcers: at the 13th International Leprosy Congress in the Hague in 1988, 23 panels reported good results in many treatments used for the healing of plantar ulcers (casting, zinc, collagene, hydrocolloid, epidermal skin, graft, island, flaps . . .) but it is well known that the biggest problem in insensitive foot is not the healing of plantar ulcers which can very often heal by rest (bed rest or plaster cast) and anything else, but always by rest, even if sometimes the healing time is shortened by some days. The problem is how to prevent their recurrence.

Curative plastic surgery: Excision-suture, local island flaps (sometimes with skin of a toe from which infected bone and joint has been removed) can shorten the healing time but recurrences are frequent. To prevent recurrence some procedures try to suppress the mechanical factor of ulcers.

Modification of elective high pressure sites of the sole. It is well known that plantar ulcers occur under prominent bones either anatomical, as tubercle of the base of the fif th metatarsal and of the calcaneus or secondary to deformities as metatarsal heads, exposed by clawed toes, or lateral border of a varus drop foot (in 1960 a record of 1049 plantar ulcers ${ }^{51}$ showed that $78 \%$ occur under metatarsal heads or in the tip of the toes, $8 \%$ under the tubercle of the base of the fifth metatarsal and $12 \%$ under great calcaneal tubercle).

Protective footwear: the aim is to distribute the weight over the maximum area of plantar insensitive skin, to relieve the insensitive and/or scarred areas from weight bearing and to be moulded on deformed and even shortened feet. ${ }^{24-66}$ This is obtained by using an insole of microcellular rubber or of plastazote which can be moulded. The footwear should be produced in large numbers, at a low cost, and if possible sold to all people in the market, then modified (insole) by a local shoe-maker. It should also be acceptable to the patients, without identifying them as suffering of leprosy. From the three designs of footwear-for feet with ulceration and shortening, for insensitive feet with some deformity and for insensitive but not deformed feet, the latter is the design which can satisfy all the required conditions. Thus, cost effectiveness should give priority to the provision of footwear to the greater number of insensitive but not deformed feet.

Corrective surgery for deformities. ${ }^{8,47,51,61}$

Correction of claw toes: it prevents ulcers under metatarsal heads and also in the tip of the toes.

Correction of foot drop: it prevents ulcers on the lateral side of the foot.

Removal of bony prominences: ${ }^{8} 15$ Plantar calcaneus tubercle: its removal enlarges the plantar weight-bearing surface of calcaneus and lowers the pressure per unit on the skin of the heel.

Tubercle of the base of the fif th metatarsal: its removal suppresses high pressure when this tubercle has excessive size.

Metatarsal heads: even if the healed ulcers under them will not recur after their removal, the weight-bearing surface is deplaced proximally under the tip of the remaining metatarsal bone. So it seems to be not a very logical procedure except when there is infection of joint or protrusion of a single metatarsal head. If not, correction of the clawtoes is the choice.

Prophylactic surgical tibialnerve decompression. After Reginato published his paper in 1962, I have performed this decompression which prevents the occurrence or recurrence of plantar ulcers even when they are long standing. The results were published in $1969,8.28$ $1976^{29}$ and $1979 ;{ }^{30}$ in some cases partial sensory recovery occurred. The best results ${ }^{23}$ were observed in patients with only insensitive sole of the foot or a first ulcer healed. Therefore 
it would be particularly judicious to look for plantar sensory loss and to take into account 'grade 1' particularly in every case of reaction. Of course, this decompression cannot secure improvement or healing of superinfected tissues and bones. The healing of long standing plantar ulcers without any clinical sensory recovery was explained by the simultaneous decompression of posterior tibial vessels and by the section of local sympathetic nerve supply to the artery when the nerve is separated from the artery.

Nevertheless "nerve decompression does not rule out the need for corrective operations: removal of prominent bones, palliative surgery of foot drop or claw toes ${ }^{8-28}$ (and the provision of standard or protective footwear).

Palande in $1975,{ }^{58}$ Van Droogenbroeck in 1977, Pandya in 1978, Kumar in 1985, and others, have also published their results.

\section{THERA PEUTIC SURGERY}

\section{Surgical nerve decompression}

Sometimes medical treatment is not sufficient to improve nerve involvement or nerve damage, even if nerve rest by suitable splint or plaster cast has been used. To prevent definitive nerve damage and thus deformities and mutilations, it is clear that surgery can suppress the superadded mechanical external and internal compression as first proposed by Guadagnini ${ }^{49}$ in 1953.

There are differences of opinion concerning its usefulness: perusal of literature shows that this nerve surgery has been done for a long time by many authors, with good results; but many others have reported good results with the medical treatment only and they consider the indications for neurolysis have been much reduced. Nevertheless, it may be observed that medical treatment only may have drawbacks: consumption of analgesics may be excessive, mainly because of neuritic pain. This consumption is rarely taken into account in published studies; corticosteroids regimens are not yet well defined. Steroid treatment needs frequent and prolonged hospitalization interfering with the individuals' ability to lead a normal life; large doses lead to serious morbidity; they have their own side-effects and many patients develop dependancy. It is well known that long-standing corticosteroid regimens may favour stress fractures, delayed wound healing and increase of susceptibility to other infections such as tuberculosis. But in leprosy there are no studies about its impact on decalcification of bones, stress fractures and the super-infection of wounds and ulcers. Thalidomide also has side-effects in addition to its teratogenic effect and to procure thalidomide very often raises difficulties. Failures of thalidomide with relapses has led to the use of cyclosporine $\mathrm{A}$, which has significant side-effects and thalidomide itself may produce sensory polyneuropathy. In some published cases (but how many are unpublished?) of corticosteroid treatment, sometimes prolonged for more than 1 or even 2 years, there was no recovery and if nerve surgery is then performed, it is useless. In some of these cases, in which pain was finally relieved, we might say that medical treatment would have eventually improved it in time, but decreased pain is not necessarily an indication of improvement of the nerve, because pain may decrease as nerve function decreases. ${ }^{15,17,18}$ In these cases, earlier surgical nerve decompression might give recovery and therefore shorten the duration of corticosteroid treatment of neuritis. Indeed, some 'good' results of MDT in a country where experienced surgeons are available, have recently been published 'with no disability noted of more than grade 1'. 
What will be the evolution of these grade 1 disabilities, 3 or 5 years later? Because disabilities in anaesthetic limb extremities may appear after many months or years, these 'grade 1' cases should be seen at regular intervals for follow-up examination, for at least 2 years after release from MDT. ${ }^{5-67}$

However, many therapists still have doubts about the efficiency of nerve decompression. They think it is not possible to determine whether nerve surgery will give better results than medical treatment alone. There are two main explanations for their doubts: (1) Although for more than 30 years good results of nerve surgery in leprosy have been reported by many authors, these authors have not had the same data and methods of evaluation (a prospective study about nerve surgery needs to be made in large centres). (2) Sometimes, quite sincere therapists, who have asked surgeons for nerve decompression, have thought an immediate result of surgical decompression was a failure because they did not appreciate that recovery is not immediate. When there is partial function loss, early decompression may give rapid recovery in some weeks. Usually, however, recovery duration is longer than that observed after nerve suture: one millimetre advancement from the decompression site every day. This duration is longer for ulnar nerve than for median nerve ${ }^{8-12}$ and in many cases there are possibilities of late recovery, $1 \frac{1}{2}$ or 2 years after. But in leprosy, lesions are not uniform, some fasciculi only compressed may recover after decompression, while other destroyed fasciculi do not recover; and recovery is not as regular or as predictable as after nerve suture or after decompression of an entrapment neuropathy.

Strategy and tactics: To give good results, nerve surgical decompression has to be made before nerve damage becomes definitive (the sooner the decompression the earlier the recovery), and in hyperacute painful neuritis or in reversal neuritis, time-lag range may be a few days or weeks. Thus, in many cases, time must not be lost. To make this surgery possible in the field (where, even now, relatively unskilled staff use only clinical findings to classify patients but where sometimes a surgeon is available in a nearby district hospital), it is necessary: (1) to use a standard technique:8,12,13 it could be external decompression with tunnel opening, and internal decompression by longitudinal incision of the sheath in its superficial aspect over the swelling with medial and lateral resection of a quarter of the thickened sheath. (In 1957 and 1962 Carayon $^{37,38,41}$ proposed internal decompression by fascicular endoneurolysis and for him, 'endoneural liberation is the essential step', nevertheless this is a neurosurgical procedure for specialized surgeons in specialized centres ${ }^{39}$ and it is not adapted to technical field conditions.) (2) To have simple indications: $:$, 12,17,18 the right time to operate would be the time after which acute pain and/ or sensory and motor loss go on or grow worse after the beginning of medical antiinflammatory treatment associated with splinting. (Time lag range: 8-10 days for hyperacute painful neuritis; 8-10 weeks for reversal neuritis and 8-10 months for ENL neuritis.) As I have proposed for many years, ${ }^{16}$ this implies a neurological examination which is easy to do, rapid but reliable, liable to be often repeated, to look for clinical aggravation. Simpler indications could be: hyperacute neuritis with intractable pain, and/ or first plantar ulcer (which is evidence of plantar sensory loss).

No postoperative worsening of paralysis was found but recovery of the whole of sensitivity cannot be obtained in all cases (the la ter we operate the less recovery we get) but rate of recovery can often be 40 to $60 \%$ and this protective sensitivity is very important to prevent disabilities and mutilations. The medical treatment must be continued. This easily carried out decompression surgery is not a luxury at all, it must be done whenever it is 
possible, it avoids occurrence of mutilations, is cheaper than repeated dressing on a lifelong basis. And even if a surgeon would only operate on leprosy patients with hyperalgic reactional neuritis or with first recent ulcer, when medical treatment is not sufficient, these cases constitute half the indications.

\section{Conclusion}

Surgery does not claim to be the first priority in the treatment of leprosy patients. Nevertheless, in leprosy, many problems can be partly solved by surgery and when a surgeon is available in the environment in which the disabled patient lives, reconstructive, cosmetic, salvage and therapeutic surgery can give better results, earlier, and often be cheaper than a lifetime of dressings and physiotherapy. Indeed, even if what I wrote in 1969 at the end of my paper relating to francophone Africa about leprosy surgery ${ }^{8}$ was a little enthusiastic it holds true now.

'Owing to the very limited number of specialized leprosy surgery centres, to the budgetary difficulties of the hospitalization, these leprosy patients have to be treated on the spot by non-specialized surgeons of the district. In other words, we need simple and quick techniques, not needing long hospitalization, or significant postoperative reeducation, enabling us to treat a greater number at less cost. As a conclusion, we can see that a surgeon able to carry out some neurolyses, using only four simple and efficient interventions of palliative surgery, can thus prevent or cure deformities in $90 \%$ of (recent) leprosy patients and bring them back to a normal life'.

75 Boulevard Charles Livon

P. BourRel 13007 Marseille

France

\section{References}

1 Andersen JC. Foot drop in leprosy. Lepr Rev, 1964; 35: 41-6.

2 Andersen JG, Brandsma W. Keep those hands mobile. Lepr Rev, 1980; 51: 251-4.

3 Antia NH. Reconstructive surgery of the face, pp. 497-509. In: Leprosy in theory and practice, Vol. 1. Cochrane RG, Davey TF (eds). Bristol: John Wright and Sons Ltd, 1964.

${ }^{4}$ Bechelli LM, Walter J. Assessment of the importance of reconstructive surgery of leprosy from the public health point of view. Acta Lepr, 1971; 45: 5-30.

5 Becx-Bleumink M. The management of nerve damage in the leprosy control services. Lepr Rev, 1990; 61: 111.

${ }^{6}$ Bourrel P. Transplantation du jambier postérieur sur le jambier antérieur et du fléchisseur commun des orteils sur l'extenseur du gros orteil et l'extenseur commun des orteils dans les paralysies S.P.E. A propos de 27 observations. Ann Chir, 1967; 21: 1451-60.

7 Bourrel P. Personal experience of surgical treatment of leprous paralyses and proposal of a therapeutic scheme. Int J Lepr, 1968; 36: 615.

8 Bourrel P. Chirurgie de la lèpre chez l'Africain. Expérience personnelle de 580 interventions. Méd Trop, 1969; 29: $1-32$.

- Bourrel P. Raccourcissement capsulaire et avancement de la poulie des fléchisseurs dans les paralysies des muscles intrinsèques des doigts. Ann Chir Plast, 1970; 15: 27-33.

${ }^{10}$ Bourrel P. Neurographies. Techniques-Intérêt-Limites. Revue Chir Orthop, 1974; 60: 89, 96.

11 Bourrel P. Transfert de l'extenseur propre de l'index pour restaurer l'opposition du pouce. Méditerranée Méd, 1978; 177: 5-6. Méd Trop, 1979; 39: 88-90. Acta Lepr, 1982; 88: 74-7.

12 Bourrel P. Chirurgie directe de la névrite lépreuse. Méd Trop, 1980; 40: 451-3. 
13 Bourrel P. Techniques de neurolyse des névrites lépreuses hyperalgiques. Extrait du livre Techniques élémentaires pour médecins isolés, tome I: Techniques chirurgicales, par les Agrégés du Pharo. D.G.D.L.Ed diffusion Maloine, 1981; 161-6.

14 Bourrel P. L'opération de Thompson pour rétablir l'opposition du pouce. Méd Trop, 1982; 42: $223-4$.

15 Bourrel P. Place de la chirurgie dans le traitement et la réhabilitation des lépreux. Chirurgie (Mémoires de l'Académie), 1982; 108: 744-52.

16 Bourrel P. Examen neurologique rapide dans les névrites lépreuses. Acta Le pr, 1982; 86: 235-41.

17 Bourrel P. Surgical rehabilitation and surgical prevention of leprosy deformities. Quaderni di cooperazione sanitaria 1983; 1: 131-44.

18 Bourrel P. Leprosy surgery: strategic and tactics. Transactions of the XII International Congress, 1984, pp. 385-7 and Acta Lepr, 1984; 94: 55-63.

19 Bourrel P. Fiche de chirurgie palliative dans la lèpre. Méd Trop, 1984; 44: 171-8 and Acta Lepr, 1985; V: 7786.

${ }^{20}$ Bourrel P. The metacarpophalangeal stabilization test, Beevor or Bouvier. Ann Chir Main, 1985; 4: 31-5.

${ }^{21}$ Bourrel P. Paralysies lépreuses des intrinsèques. Ann Chir Main, 1986; 5: 226-8.

22 Bourrel P. Interventions palliatives pour correction des griffes des doigts. Ann Chir Main, 1986; 5: $230-41$.

${ }^{23}$ Bourrel P. Prospective et recherche thérapeutique dans les maux perforants plantaires. Acta Lepr, 1986; V: 45-8.

24 Bourrel P. Recours chirurgicaux dans les lésions neurotrophiques de la lèpre. Chirurgie, 1988; 114: 545-60 et Acta lepr, 1990; 7: 175-91.

25 Bourrel P, Carayon A, Languillon J. La transplantation des fléchisseurs superficiels dans 74 cas de paralysie lépreuse des muscles intrinsèques de la main. Rev Chir Orthop, 1961; 47: 484-503.

26 Bourrel P, Carayon A, Languillon J. Deux nouvelles techniques de traitement des paralysies des muscles intrinsèques de la main: l'operation de Brand, l'opération de Zancolli. A propos de 19 observations personnelles. Ann Chir 1962; 16: 81-8.

27 Bourrel P, Giraudeau P, Bourges M. Vingt ans de chirurgie de la lèpre à l'institut Marchoux de Bamako. Ann Chir Plast, 1979; 25: 190-6.

28 Bourrel P, Bourges M, Giraudeau P. Neurolyse du nerf tibial postérieur au canal tarsien dans le traitement des maux perforants plantaires lépreux. Perspectives de recherche pour d'autres neuropathies. Ann Chir Plast, 1969; XIV: 212-17. Acta lepr, 1970; 40:91-4. Neurolysis of the posterior tibial nerve in the tarsal tunnel in the treatment and prevention of neuropathic ulceration of the foot. Int J Lepr, 1973; 41: 602.

29 Bourrel P, Rey A, Blanc JF, Palinacci JC, Bourges M, Giraudeau P. Syndrome du canal tarsien. A propos de 15 cas «purs» et de 100 cas «associés» à la lèpre ou au diabète. Rev Rhurn, 1976; 43: 723-8.

30 Bourrel P, Rey A, Blanc JF, Palinacci JC, Bourges M, Giraudeau P. Syndromes du canal tarsien. A propos de 20 cas «purs» et de 150 cas «associés». Méd Hyg, 1978; 1281: 1198-1202.

31 Brand PW. Paralytic claw hand. J Bone Joint Surg, 1958; 40B: 618-32.

32 Brand PW. Tendon grafting. Illustrated by a new operation for intrinsic paralysis of the fingers. J Bone Joint Surg, 1961; 43B: 444-53.

${ }^{33}$ Brand PW. Deformity in leprosy, pp. 447-96. In: Leprosy in theory and practice, Vol. 1. Cochrane RG, Davey TF (eds). Bristol: John Wright and Sons Ltd, 1964.

34 Brand PW. Reach out. The Star, 1980; 39: 3.

35 Brand PW, Fritschi EP. Rehabilitation in leprosy, Ch 14, pp. 287-319. In: Leprosy. Hastings RC (ed). Edinburgh, 1985.

36 Brand PW, Selvapandian. Transposition of the tibialis posterior in foot drop deformities. Ind J Surg 1960: 21: 157-60.

37 Carayon A. La neurolyse fasciculaire, application aux lésions nerveuses periphériques en continuité (lépre trauma, tumeurs). J Chir (Paris), 1962; 3: 435-72.

38 Carayon A. Chirurgie directe des gros troncs dans la lèpre. J Chir (Paris), 1970; 99: 235-74.

39 Carayon A. Conduite pratique actuelle devant une névrite hansénienne. Acta Le pr, 1980; 79: 67-73.

40 Carayon A, Chippaux-Mathis J, Megh E. Nouvelle intervention palliative pour pied équin paralytique. Rev Méd Chir A Ex-Orient, 1953; 1: 24-8.

41 Carayon A, Huet, R. La névrite lépreuse et ses complications. Méd Trop, 1957; 17: 496-541.

42 Chaise F. Evaluation des pressions canalaires et sous épineurales dans les syndromes de souffrance d u nerf médian lépreux au poignet. Ann Chir Main, 1984; 3: 271-4.

43 Chevallard AJ. Simplified surgical technique for flexible clawed hand rehabilitation. Int J Le pr, 1987; 55: 1602.

${ }^{44}$ Enna CD. The use of injectable silastic as a prosthetic material for muscle atrophy of the thumb web in leprosy. Int J Lepr, 1966; 34: 30-3.

45 Enna CD, Riordan DC. The Fowler procedure for correction of the paralytic clawhand. Plast Reconstr Surg, 1973; 52: 352-60.

46 Faget GH, Mayoral A. Bone changes in leprosy. A clinical and roentgenologic study of 505 cases. Radiology, 1944; 42: 1 . 
47 Fritschi EF, Brand PW. The place of reconstructive surgery as prevention of the foot ulceration in leprosy. Int J Leprosy, 1957; 25: 1.

48 Giraudeau P, Carayon A. Traitement palliatif des paralysies des intrinsèques des doigts par le grand palmaire prolongé par quatre bandelettes de fascia lata. A propos de 23 observations. Rev Chir Ortho, 1971; 57: 14550 .

49 Guadagnini M. Lepromatous neuritic lesions, their great incidence in certain sensory and motor branches, and their treatment. Lepr Rev, 1953; 24: 147-55.

50 Gye RS, McLeod JG, Hargrave JC, Pollard JD, Loewenthal J, Booth GC. Use of immunosuppressive agents in human nerve grafting. Lancet, 1972; 1: 647-50.

51 Languillon J, Bourrel P, Boissan R, Picard P. Contributions à l'étude des maux perforants plantaires lépreux. Distribution, étiologie, pathogénie, complications traitement. Méd Trop, 1960; 20: 219-55.

52 Lennow WM. Plastic surgery of the anaesthetic foot of leprosy. Lepr Rev, 1965; 36: 109-17.

${ }^{53}$ Lennow WM. Use of a neurovascular skin island pedicle graft in the management of the anaesthetic hand in leprosy. JBJS, 1966; 48B: 198.

${ }^{54}$ McLeod JG, Hargrave JC, Gye RS, Pollard JD, Walsh JC, Little JM, Booth GC. Nerve grafting in leprosy. Brain, 1975; 98: 203-12.

55 Noordeen SK. The challenge of leprosy. Ind J Lepr, 1988; 60: 149-58.

56 Ober FR. Tendon transplantation in the lower extremity. New Engl J Méd, 1933; 209: 52-9.

57 Palande DD. A revue of 23 operations on the ulnar nerve in leprous neuritis. J Bone Joint Surg, 1973; 55A: 1457-61.

58 Palande DD. Surgical decompression of posterior tibial neurovascular complex in treatment of certain chronic plantar ulcers and posterior tibial neuritis in leprosy. Int $J$ Lepr, 1975; 43: 36-40.

59 Palande DD. Correction of intrinsic minus hands associated with reversal of the transverse metacarpal arch. J Bone Joint Surg, 1983; 65A: 514-21.

${ }^{60}$ Reginato LE, Belda W, Canton P, Faggin JE, Cruz E, Almeida NG, de Mendes FC. A epineurectomia do tibial posterior no tratamento do mal perforante plantar de origen leprosa. Rev Bras Lepr, 1962; 5: $103-10$.

${ }^{61}$ Ross WF, MacLean HH. Surgery and the prevention of the planter ulcers. Lepr Rev, 1964; 35: 59-60.

62 Sharangpani RC, Kulkarni VN, Metha JM. A new approach in muscle training to rehabilitate the hand in leprosy. Ind J Lepr, 1985; 57: 750-5.

63 Srinivasan $\mathrm{H}$. The extensor diversion graft operation for correction of intrinsic minus fingers in leprosy. $J$ Bone Joint Surg, 1973; 24: 632.

${ }^{64}$ Srinivasan H. Dermadesis and flexorpulley advancement in leprosy patients. $J$ Hand Surg, 1985; 10: 979-82.

65 Watkins MB, Jones JB, Ryder CT, Brown TN. Transplantation of the posterior tibial tendon. J Bone Joint Surg, 1954; 36A: 1181-9.

${ }^{66}$ Watson JM. Preventing disability in leprosy patients. The Leprosy Mission International, 1986.

67 Watson JM. Disability control in a leprosy control program. Lepr Rev, 1989; GO, 169-77.

${ }^{68}$ Zacharia AG, Gelber RH. Silastic implant of the first dorsal interosseous space. Int J Le pr, 1985; 53: 643-4.

${ }^{69}$ Zancolli EA. Claw hand paralysis of the intrinsic muscles. J Bone J Surg, 1957; 39A: 1979-80.

70 Zancolli EA. Structural and dynamic bases of hand surgery. London: Pitman Medical Publishing Co, Ltd. Philadelphia: J.B. Lippincott Company, 1968.

71 Zancolli EA. Correction de la gara digital por paralisis intrinseca. La operation del «Lazo». Acta Orthop Latina, 1974; 1: 65-72. 